\title{
PHYSICAL EXERTION MONITORING: ELITE ATHLETES MODIFY THEIR COACH'S TASK
}

\author{
Artūras Sujeta, Kristina Poderienė, Jonas Poderys \\ Lithuanian Sports University, Kaunas, Lithuania
}

\begin{abstract}
Background. The objective of this study was to establish how accurately elite athletes carried out the task of a coach to perform an exercise at a given intensity.

Methods. Cardiovascular indices were registered and analysed during a two-step research process. Two groups including six well-trained long-distance runners and 21 healthy non-athletes performed graded stress exercise up to the inability to continue the task. Runners took part in the second study in which heart rate and running pace were recorded during an aerobic training session.

Results. Research findings showed that athletes demonstrated higher physical performance, but the maximum heart rate values achieved in the last fatigue phase did not differ significantly between the groups. No ischemic events were observed in elite athlete group during the entire physical test. Relatively stable heart rate indices in the maximal physical load step were observed in both groups, but heart rate indices were significantly lower during all physical load steps in the group of elite runners.

Conclusions. Elite athletes carried out the coach's task only in the first phase of running and further modified the task by maintaining the stability of the cardiovascular system.
\end{abstract}

Keywords: training, cardiovascular system, functional state, heart rate.

\section{INTRODUCTION}

$\mathrm{T}$ The complex system approach is based on the understanding that the human body is a self-regulating system, and many factors determine the behaviour of the entire system. The cardiovascular system is a vital part of the body, and its complexity and interrelationship with all body systems allow the monitoring of cardiovascular parameters as feedback of applied influences.

It is generally accepted that various factors determine training effects. A quantified doseresponse relationship for the continuum of training intensities, frequencies, and volumes was identified for fans of healthy lifestyle populations, but this relationship has not been identified for elite athletes (Peterson, Rhea, \& Alvar, 2004; Seiler \& Kjerland, 2006). Sports training is the process of adaptation, the efficiency of which can be increased by manipulating training loads. Therefore, the precise workload parameters while exercising are one of the essential components of effective training (Gaudino et al., 2013).

Functional status of fans of healthy lifestyles and high-performance athletes changes during exercise, and the mechanisms of these changes are partially different and individualized. Additional monitoring and recording of internal and external load parameters can improve the quality of health observations and also provide better knowledge of the optimal dose of training load during exercise (Shephard \& Blady, 1999; Weiner et al., 2011).

Aerobic-type exercise triggers many short-term and long-term adaptive changes. Cardiovascular changes in athletes depend on the nature of the activity, the length of training and other factors (B. J. Nainmark, A. Naimark, Tate, Sigurdsson, \& Axelsson, 1996). Scientists assign 
long-distance runners as typical aerobic endurance training athletes, who have one of the largest hearts, to calculate mass and other parameters for each kilogram of their body weight (Fagard, 1997; Fagard et al., 1983; Urhausen, Monz, \& Kindermenn, 1997). Some authors consider the heart rate response measurement as a convenient non-invasive evaluation tool to monitor and analyse individual workouts (Dellal et al., 2012; Hettinga, Monden, van Meeteren, \& Daanen, 2014; Jeukendrup \& VanDiemen, 1998). Various types of heart rate monitors were widely used in endurance sports for over 30 years (Achten \& Jeukendrup, 2003). Optimum performance level depends on the development of body responses through training. Therefore, one important task of physiological research is to effectively evaluate and monitor the training schedule (Alexandre et al., 2012; Ghosh, 2004).

The task of a training session is the infliction of internal body changes. A coach must first consider the type of internal body changes and the proper approach to provoke the planned changes in athlete's body during the planning of physical loads. Continuous methods are widely used in endurance training. It is important to continue task performance under fatigue by increasing the conditions that trigger long-term adaptation mechanisms. One of the important questions in training methodology is how accurately athletes perform the given task or how they modulate the given task of a training session. Therefore, the accurate accomplishment of the task given by the coach is very important. This study assessed how accurately elite athletes carried the task of their coach to "run $12 \mathrm{~km}$ at a steady speed".

\section{METHODS}

Internal body changes are a trigger for longterm adaptation. The purpose of each training session is to make appropriate internal body changes, and the coach's task is to plan the mode of exercise. However, internal body changes at the onset of exercising depend on individual features of the athletes, and the monitoring of the body's response during exercising is one manner to obtain feedback.

There are two ways to monitor the external performance of tasks, such as the dynamics of running speed or the dynamics of HR changes during exercise. Both parameters are important in our approach because they can reveal important features of the essence of the training session.

Subjects. Two groups of participants were involved in the study. The first group consisted of elite endurance runners (age $20.9 \pm 1.21$, body mass index $22.3 \pm 0.38 ; n=6$ ). The second group consisted of healthy male non-athletes (age $23 \pm$ 1.8 years, body mass index $24.4 \pm 1.3 ; n=21$ ). All subjects provided their written informed consent before participation in the study.

Procedures. The first study was designed to compare the functional abilities of the two groups in this study. All participants performed bicycle ergometry, i.e., a graded exercise test up to the inability to continue the task. A 12lead electrocardiogram provided continuously recording during exercise and the first three minutes of recovery.

The second study was designed to study exercise task accuracy accomplishment. A group of elite runners performed a task to run a $12-\mathrm{km}$ distance at a steady running speed in an aerobic zone. The heart rate monitor Polar-S810 monitored heart rate changes (instantaneous heart rate values, average heart rate (HR avg.), values of the selected section (each $1000 \mathrm{~m}$ ), and optional sections of running time (t) (every $1000 \mathrm{~m}$ running time).

Statistical analysis. The arithmetic mean (x) and standard deviation (s) and the arithmetic mean of the error $\left(\mathrm{s}_{\mathrm{x}}\right)$ were calculated. A two-way independent samples Student's $t$-test was used to determine the reliability of the mean difference in performance indicator results. A significant difference between the compared values was indicated when the error did not exceed 5\% $(p<.05)$.

\section{RESULTS}

The results obtained during the first study showed a significant difference between groups in physical working capacity. The healthy male non-athletes continued exercising up to $250 \mathrm{~W}$, and the elite athletes continued exercising up to $350 \mathrm{~W}$. The mobilization of cardiovascular function during the workload was described using HR changes (Figure 1). A significant increase in HR was observed in both groups during the graded exercise test up to inability to continue the task, and this increase continued according to the increasing workload. The endurance runners' HR was significantly lower at rest and during the entire test than non-athletes (before the load at 
rest $-87.6 \pm 2.8$ in the group of non-athletes and $71.7 \pm 2.5$ in the group of endurance runners; on the last minute load $-172.3 \pm 3.0$ in the group of nonathletes and $170.7 \pm 0.8$ in the endurance runners' group). The investigation established that athletes had higher physical performance but maximum HR values in both groups when the full fatigue phase was achieved, but these values did not differ significantly. Faster HR recovery was observed in the group of endurance runners during the recovery time.

The ST-segment depression increased with each step of increasing workload in the group of non-athletes. These types of changes were not observed in elite runners' group. The results indicate that ischemic episodes were observed in the group of non-athletes, and there were no ischemic episodes in the group of elite runners. STsegment depression changes (Figure 2) show that the workload reached its maximum values during the highest physical test loads in both groups (in the non-athletes' group it was recorded at $250 \mathrm{~W}$, ST-segment depression $-0.53 \pm 0.13 \mathrm{mV}$; in the runners' group - at $350 \mathrm{~W}-0.17 \pm 0.02 \mathrm{mV}$ STsegment depression).

The second study was designed to assess how accurately elite athletes carried out the task of their coach to "run $12 \mathrm{~km}$ at a steady speed". The results
Figure 1. The heart rate (HR) changes in male elite runners and non-athletes every minute in steps during incremental cycling exercise testing
Figure 2. ST-segment depression changes in male elite runners and non-athletes during the performance of graded exercise tests to maximal efforts
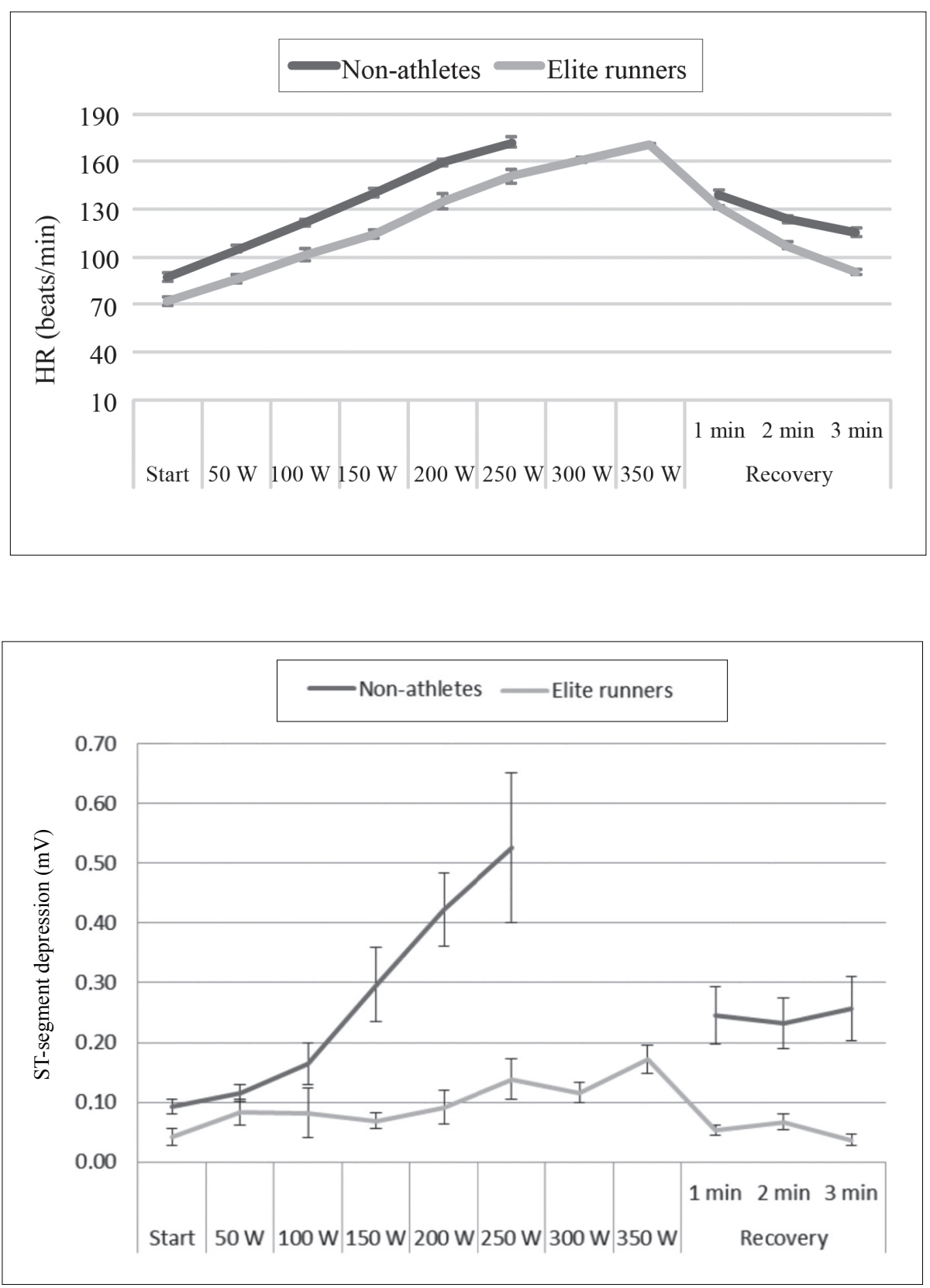


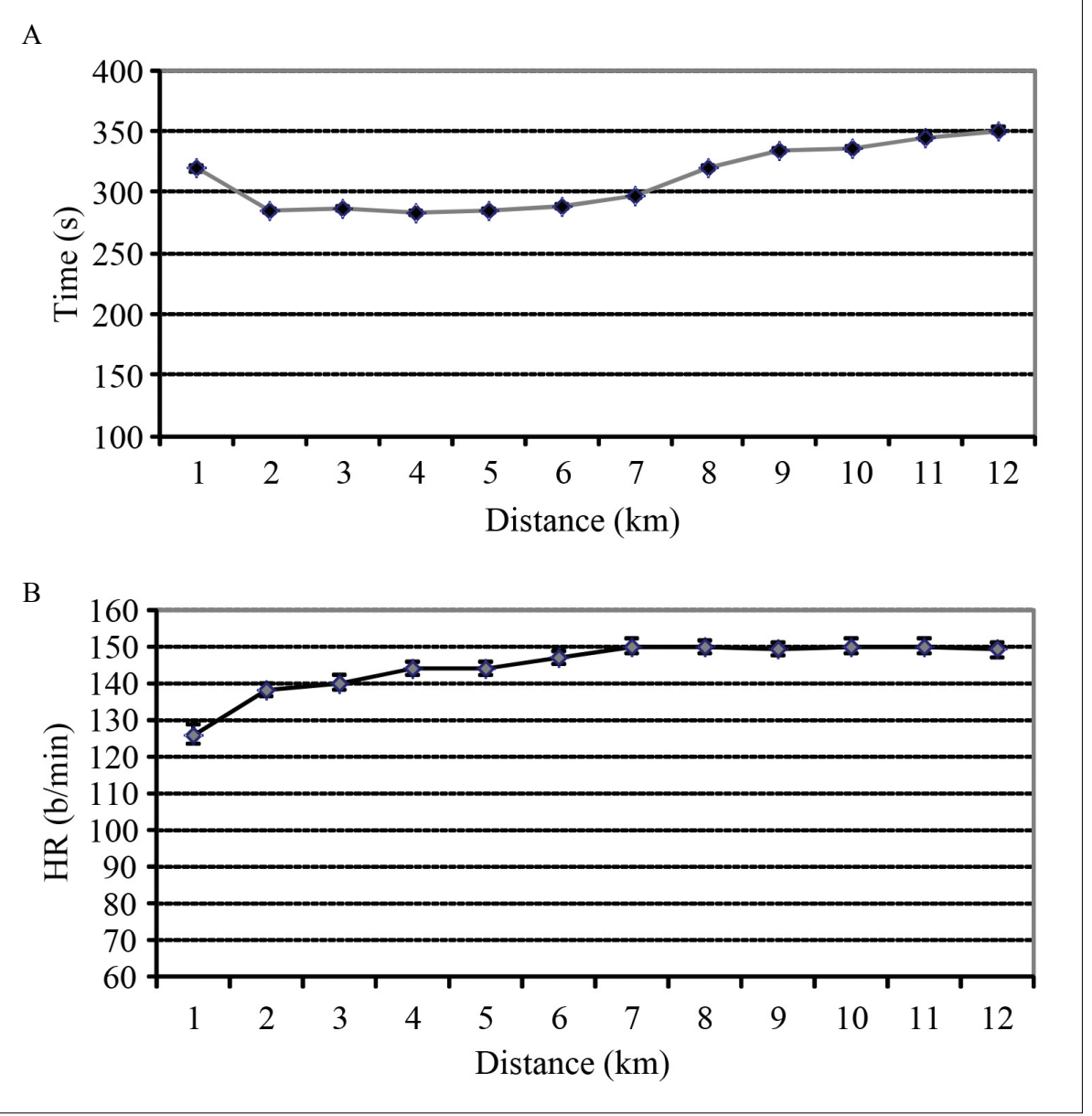

Figure 3. Indices characterizing external and internal physical loads during the task "run $12 \mathrm{~km}$ at a steady speed". A-dynamics of time of running $1 \mathrm{~km}$. B - dynamics of HR

showed that running time change was $319.8 \pm 4.8$ in the first kilometre in the endurance runners' group, and the change in the last kilometre was $350.7 \pm 3.4$. A fairly equal rising segment speed was maintained during the middle distance (Figure $3 \mathrm{~A}$ ).

HR dynamics (Figure $3 \mathrm{~B}$ ) during the run in the first kilometre revealed an average HR of $126.0 \pm 2.6$ beats $/ \mathrm{min}$ and $149.0 \pm 2.0$ beats $/ \mathrm{min}$ in the final kilometre. The submitted change in HR curve during the second half of the running task, i.e., from the $7^{\text {th }}$ kilometre of running, revealed no significant HR variations, i.e., the task to run was performed without changes in HR.

\section{DISCUSSION}

Exercise is one of the most powerful nonpharmacological strategies that affects most cells and organs in the body (Shalaby, Saad, Akar, Reda, \& Shalgham, 2012). Regular aerobic exercise has a positive long-term impact on the cardiovascular system, which is a vital part of the body because it is a biologically complex adaptive system that is characterized by a variety of complex reactions to training loads (Alex et al., 2013; Ellison, Waring, Vicinanza, \& Torella, 2012; Gibala, Little, MacDonald, \& Hawley, 2012).

Biological systems consist of numerous different components that are linked together to form a complex system characterized by non-linear dynamics (Pinsky, 2010). However, a system of self-regulation that leads to a single factor within the system does not exist because it determines the entire system. The complexity of this regulation cannot be appreciated if the body is studied as a collection of disconnected components, which is the usual approach in modern exercise sciences (Noakes, 2011).

External and internal physical loads have been identified. Most previous authors note that the internal side of exercising is very important in the training of physical abilities (Issurin, 2013; O'Keefe et al., 2012). Therefore, the accuracy of elite athletes' accomplishment of a task of their coach is essential for the management of the training process. The essence of the coach's planned task for a training session with a specified external workload, usually measured in SI units, is the internal body changes 
to be achieved by the performance of the assigned workloads. Notably, an internal exercise control and evaluation are the essence of individualization. HR is one of the cardiovascular functional status indicators evaluating the inner half of physical exertion. HR is also used to describe the body's common condition changes.

Advances in technology have provided athletes, coaches, and scientific as well as medical staff with mobile and easy to use heart rate monitors (Weippert et al., 2010). These monitors are widely used by elite athletes and people who exercise for health promotion. HR monitors can help a coach assess the accuracy of an athlete's performance of a given task during training, but not all of the HR monitor indicators are accurate and suitable for evaluations of high-performance athletes.

There are various methods of measuring the body reactions to exercise and physical exertion, but their applicability and value are widely discussed and analysed (Boettger et al., 2010). Doubts of an optimality index are associated with cardiovascular parameters with synergic interaction features. Increases in the severity of exercise lead to increases in HR until it reaches its maximum, which is relatively constant in a particular person. This observation was confirmed in our first study. The results of the first study showed that athletes (first group) differed from the healthy group with better cardiovascular reactions to incremental exercise stress. There were no ischemic episodes during exercising, but the lower HR values at each step of workload indicated better functional abilities that were obtained by training. This comparison showed that the participants in the elite runners group exhibited better functional readiness; the increasing workload HR values were significantly lower in elite runners than in the group of non-athletes. HR monitors can be used during highly trained runners' workout sessions to control the quality or task accuracy of the session. The results of this study showed that the runners modified the coach's designated exercise task to "run $12 \mathrm{~km}$ at a steady speed". More than half of the current distance runners maintained a steady running speed, which resulted in a gradual increase in HR, and a stable HR was maintained during the rest of the running distance; HR did not increase and running speed decreased.

Running time showed few changes during the distance when the runners performed a measured workload, which was performed in a particular operating region. The runners turned to training activity during the first kilometre, and only after the second section they began to maintain the goal of the task. A constant running speed was maintained until the middle distance, and then it declined. These results suggest that the runners began to maintain the trained zone regardless of the distance. Subsequent HR changes during the distance run were low. An HR change increased by the seventh kilometre, and HR was maintained at the same level from midway of the distance to exceed the prescribed training mode.

Measures of an athlete's heart rate have shown potential for use in the prescription of individual training. However, little data exists on elite athletes who are regularly exposed to intense training loads (Plews, Laursen, Kilding, \& Buchheit, 2012; Wallén, Hasson, Theorell, Canlon, \& Osika, 2012). Measures of heart rate cannot provide data on all aspects of wellness, fatigue, and performance. Therefore, the use of HR in combination with daily training logs, psychometric questionnaires and noninvasive, cost-effective performance tests, such as a countermovement jump, may offer a complete solution to monitor the training status of athletes participating in aerobic-oriented sports (Buchheit, 2014). Our data also confirmed the results obtained by other researchers, who observed a lower degree of functional ischemic events in cardiac muscle in a group of trained athletes (Gademan et al., 2012; Poderys, Buliuolis, Poderytè, \& Sadzevičienè, 2005).

\section{CONCLUSION}

Monitoring is an important part of the management of training processes. The monitoring of running pace and internal body changes during a training session will allow the control of how accurately athletes perform a given task. Even welltrained athletes carried out the coach's task only in the first part of running and further modified a given task for training sessions by adapting themselves to internal feelings and decreasing their running pace accordingly.

Acknowledgments. The authors would like to acknowledge all our participants for their contribution in the study. This research project received no external financial assistance. None of the authors have any conflict of interest. 


\section{REFERENCES}

Achten, J., \& Jeukendrup, A. E. (2003). Heart rate monitoring: Applications and limitations. Sports Medicine, 33, 517-538. Retrieved from http://www. ncbi.nlm.nih.gov/pubmed/12762827

Alexandre, D., da Silva, C. D., Hill-Haas, S., Wong, del P., Natali, A. J., De Lima, J. R., ... Karim, C. (2012). Heart rate monitoring in soccer: Interest and limits during competitive match play and training, practical application. Journal of Strength and Conditioning Research, 26, 2890-2906. Retrieved from http://www.ncbi.nlm. nih.gov/pubmed/22130401

Alex, C., Lindgren, M., Shapiro, P. A., McKinley, P. S., Brondolo, E. N., Myers, M. M., ... Sloan, R. P. (2013). Aerobic exercise and strength training effects on cardiovascular sympathetic function in healthy adults: A randomized controlled trial. Psychosomatic Medicine, 75, 375-381. doi: 10.1097/PSY.0b013e3182906810

Boettger, S., Puta, C., Yeragani, V. K., Donath, L., Müller, H. J., Gabriel, H. H., \& Bär, K. J. (2010). Heart rate variability, QT variability, and electrodermal activity during exercise. Medicine and Science in Sports and Exercise, 42, 443-448. doi: 10.1249/ MSS.0b013e3181b64db1

Buchheit, M. (2014). Monitoring training status with HR measures: Do all roads lead to Rome? Frontiers in Physiology, 5, 73. doi: 10.3389/fphys.2014.00073

Dellal, A., Owen, A., Wong, D. P., Krustrup, P., van Exse, M., \& Mallo, J. (2012). Technical and physical demands of small vs. large sided games in relation to playing position in elite soccer. Human Movement Science, 31, 957-969. doi:10.1016/j.humov.2011.08.013

Ellison, G. M., Waring, C. D., Vicinanza, C., \& Torella, D. (2012). Physiological cardiac remodelling in response to endurance exercise training: Cellular and molecular mechanisms. Heart, 98, 5-10. doi: 10.1136/ heartjnl-2011-300639

Fagard, R. H., Aubert, A., Lysens, R., Staessen, J., Vanhees, L., \& Amery, A. (1983). Noninvasive assessment of seasonal variations in cardiac structure and function in cyclists. Circulation, 67, 896-901. doi:10.1161/01.CIR.67.4.896

Fagard, R. H. (1997). Impact of different sports and training on cardiac structure and function. Cardiology Clinics, 15, 397-412. Retrieved from http://www.ncbi. nlm.nih.gov/pubmed/9276165

Gademan, M. G., Uberoi, A., Le, V. V., Mandic, S., van Oort, E. R., Myers, J., \& Froelicher, V. F. (2012). The effect of sport on computerized electrocardiogram measurements in college athletes. European Journal of Preventive Cardiology, 19, 126-138. doi: 10.1177/1741826710392669

Gaudino, P., Iaia, F. M., Alberti, G., Strudwick, A. J., Atkinson, G., \& Gregson, W. (2013). Monitoring training in elite soccer players: Systematic bias between running speed and metabolic power data.
International Journal of Sports Medicine, 34, 963-968. doi:10.1055/s-0033-1337943

Ghosh, A. K. (2004). Anaerobic threshold: Its concept and role in endurance sport. Malaysian Journal of Medical Sciences, 11, 24-36. Retrieved from http:// www.ncbi.nlm.nih.gov/pubmed/22977357

Gibala, M. J., Little, J. P., MacDonald, M. J., \& Hawley, J. A. (2012). Physiological adaptations to lowvolume, high-intensity interval training in health and disease. Journal of Physiology, 590, 1077-1084. doi: 10.1113/jphysiol.2011.224725

Hettinga, F. J., Monden, P. G., van Meeteren, N. L., \& Daanen, H. A. (2014). Cardiac acceleration at the onset of exercise: A potential parameter for monitoring progress during physical training in sports and rehabilitation. Sports Medicine, 44, 591-602. doi: 10.1007/s40279013-0141-y

Issurin, V. B. (2013). Training transfer: Scientific background and insights for practical application. Sports Medicine, 43, 675-694. doi: 10.1007/s40279-013-0049-6 Jeukendrup, A., \& VanDiemen, A. (1998). Heart rate monitoring during training and competition in cyclists. Journal of Sports Sciences, 16, 91-99. doi:10.1080/026404198366722

Nainmark, B. J., Naimark, A., Tate, R. B, Sigurdsson, S. B., \& Axelsson, J. (1996). Cardiac structure and exercise blood pressure in urban and rural Canadian men of Icelandic descent. American Journal of Hypertension, 9, 1104-1109. Retrieved from http:// www.ncbi.nlm.nih.gov/pubmed/8931836

Noakes, T. D. (2011). Time to move beyond a brainless exercise physiology: The evidence for complex regulation of human exercise performance. Applied Physiology, Nutrition, and Metabolism, 36, 23-35. doi: 10.1139/H10-082

O'Keefe, J. H., Patil, H. R., Lavie, C. J., Magalski, A., Vogel, R. A., \& McCullough, P. A. (2012). Potential adverse cardiovascular effects from excessive endurance exercise. Mayo Clinic Proceedings, 87, 587-595. doi: 10.1016/j.mayocp.2012.04.005

Peterson, M. D., Rhea, M. R., \& Alvar, B. A. (2004). Maximizing strength development in athletes: A metaanalysis to determine the dose-response relationship. Journal of Strength and Conditioning Research, 18, 377-382. Retrieved from http://www.ncbi.nlm.nih.gov/ pubmed/15142003

Pinsky, M. R. (2010). Complexity modelling: Identify instability early. Critical Care Medicine, 38, 649-655. doi: 10.1097/CCM.0b013e3181f24484

Plews, D. J., Laursen, P. B., Kilding, A. E., \& Buchheit, M. (2012). Heart rate variability in elite triathletes: Is variation in variability the key to effective training? A case comparison. European Journal of Applied Physiology, 112, 3729-3741. doi: 10.1007/ s00421-012-2354-4 
Poderys, J., Buliuolis, A., Poderytė, K., \& Sadzevičiene, R. (2005). Mobilization of cardiovascular function during the constant-load and all-out exercise tests. Medicina, 41, 1048-1053. Retrieved from http://www. ncbi.nlm.nih.gov/pubmed/16401962

Seiler, K. S., \& Kjerland, G. Ø. (2006). Quantifying training intensity distribution in elite endurance athletes: Is there evidence for an "optimal" distribution? Scandinavian Journal of Medicine and Science in Sports, 16, 49-56. Retrieved from www.ncbi.nlm.nih. gov/pubmed/16430681

Shalaby, M. N., Saad, M., Akar, S., Reda, M. A., \& Shalgham, A. (2012). The role of aerobic and anaerobic training programs on $\mathrm{CD}(34+)$ stem cells and chosen physiological variables. Journal of Human Kinetics, 35, 69-79. doi: 10.2478/v10078-012-0080-y

Shephard, R. J., \& Blady, G. J. (1999). Exercise as cardiovascular therapy. Circulation, 99, 963-972. doi: 10.1161/01.CIR.99.7.963

Urhausen, A., Monz, T., \& Kindermenn, W. (1997). Echocardiographic criteria of physiological left ventricular hypertrophy in combined strength and endurance-trained athletes. International Journal of Cardiovascular Imaging, 13, 43-52. Retrieved from http://www.ncbi.nlm.nih.gov/pubmed/9080238

Wallén, M. B., Hasson, D., Theorell, T., Canlon, B., \& Osika, W. (2012). Possibilities and limitations of the Polar RS800 in measuring heart rate variability at rest. European Journal of Applied Physiology, 112, 11531165. doi: 10.1007/s00421-011-2079-9

Weiner, R. B., Hutter, A. M., Wang, F., Kim, J. H., Wood, M. J., Wang, T. J., ... Baggish, A. L. (2011). Performance of the 2010 European Society of Cardiology criteria for ECG interpretation in the athlete. Heart, 97, 1573-1577. doi: 10.1136/hrt.2011.227330

Weippert, M., Kumar, M., Kreuzfeld, S., Arndt, D., Rieger, A., \& Stoll, R. (2010). Comparison of three mobile devices for measuring R-R intervals and heart rate variability: Polar S810i, Suunto t6 and an ambulatory ECG system. European Journal of Applied Physiology, 109, 779-786. doi: 10.1007/s00421-010-1415-9 